5. Nguyễn Đức Chính, Đỗ Mai Dung, Trân Tuấn Anh, Ngô Thị Huệ. Tình hình tai nạn giao thông qua các trường hợp cấp cứu tại Bệnh viện Việt Đức 2016 - 2018. Tạp chí Y học Dự phòng, 2019, 29(8): 135-140.

6. Lương Mai Anh, Nguyễn Thị Thu Huyên, Nguyên Bích Hải. Kêt quả triển khai chăm sóc chấn thương trước viện tại Thừa Thiên Huế giai đoạn 2012-2013. Tạp chí Giao thông vận tải, 2016, 57: $134-137$

7. Douglas $\mathbf{N}$, Leverett J, Paul J, Gibson $\mathbf{M}$, Pritchard J, Brouwer K, Edwards E, Carew J, Donovan J, Bourke E, Smith E. Performance of First Aid Trained Staff using a Modified START Triage Tool at Achieving Appropriate Triage Compared to a Physiology-Based Triage Strategy at Australian Mass Gatherings. Prehosp Disaster Med. 2020 Apr;35(2):184-188.

\title{
ĐÁNH GIÁ CHỨC NĂNG THẤT TRÁI TRƯớC VÀ SAU PHẪU THUÂT BẮC CẦU CHỦ VÀNH Ở BÊ̂NH NHÂN ĐÁI THÁO ĐƯỜNG TYPE 2
}

\author{
Vũ Thị Lan', Nguyễn Quang Tuấn², Vũ Quỳnh Nga'
}

\section{TÓM TẮT}

Mục Tiêu: Đánh giá chức năng thất trái bằng siêu âm tim trước và sau phấu thuật bắc câuu chủ vành ở bệnh nhân đái tháo đường type2. Đối tượng phương pháp nghiên cứu: Nghiên cứu mổ tả cắt ngang trên 46 bệnh nhân đái tháo đường type 2 được phẫu thuật bắc cầu chủ vành đơn thuần từ $8 / 2020$ đến $8 / 2021$ tai bênh viên Tim Hà Nôi. Kết quả: Tuổi trung bình $6 \dot{6} \pm 8,73$; tỷ lệ nam/nữ là 2,83/1;43,5\% bênh nhân hút thuốc lá; tỷ lê đau ngực gắp $69,6 \%$ và NYHA III - IV chiếm $28,6 \%$.Kết quả siêu ẩm tim: Tỉ lệ rối loan vận đông vùng trước và sau phẫu thuật là $56,5 \%$ và $43,5 \%$; số vùng rối loạn trước và sau phẫu thuât là $3,52 \pm 5,39$ và $2,54 \pm 4,87$.Kết quả siêu âm tim ở nhóm $\mathrm{EF}<50 \%$ trước phấu thuật: Dd trước và sau phẫu thuật là $53.3 \pm 7,12 \mathrm{~mm}$ và $50,3 \pm 6,93 \mathrm{~mm}$. Ds trước và sau phẩu thuật là $40,4 \pm 8,44 \mathrm{~mm}$ và $36,8 \pm$ $8,05 \mathrm{~mm}$, Vd trước và sau phẫu thuật là $142,2 \pm 48,77 \mathrm{ml}$ và $124,2 \pm 38,9 \mathrm{ml}$. Vs trước và sau phẫu thuật là $77 \pm 42,13 \mathrm{ml}$ và $61,1 \pm 29,47 \mathrm{ml}$, LVMI là $135,5 \pm 44,61$ gram và 117,4 $\pm 30,17 \mathrm{gram}, \mathrm{EF}$ trước và sau phấu thuật là $39,22 \pm 8,4 \%$ và $45,83 \pm$ 13,39\% có sự cải thiện có ý nghĩa thống kê các thông số siêu âm: ĖF tăng lền đáng kể trong khi thể thể tích buồng tim, kích thước buồng tim và khối lượng cơ thất trái giảm. Riêng Nhóm EF bình thường: các thông số giảm nhưng không có ý nghĩa thống kê. Kết luân: Phẫu thuật bắc cầu chủ vầnh cải thiện đáng kể chức năng thất trái ngay sau phẫu thuật ở nhóm có EF thấp trước phẫu thuật.

Tử khóa: Pिẫu thuật bắc cầu chủ vành, đái tháo đường, chức năng thất trái.

Tứ viết tắt: $\mathrm{Dd}$ : đường kính thất trái cuối tâm trương, Ds: đường kính thất trái cuối tâm thu, EF: phân suất tống máu thất trái, RLCNTTr: rối loạn chức năng tâm trương thất trái, NYHA: phân độ khó thở

\footnotetext{
${ }^{1}$ Bệnh viện Tim Hà Nội,

Bênhh viện Bạch Mai.

Chịu trách nhiệm chính: Vũ Thị Lan

Email: lanvu1987@yahoo.com

Ngày nhận bài: 13.9.2021

Ngày phản biện khoa học: 2.11.2021

Ngày duyệt bài: 15.11.2021
}

theo hội tim mạch New York, Vd: thể tích thất trái cuối tâm trương, Vs: thể tích thất trái cuối tâm thu; LVMI: chỉ số khối cơ thất trái, TB: trung bình

\section{SUMMARY \\ EVALUATION OF LEFT VENTRICULAR FUNCTION BEFORE AND AFTER CORONARY ARTERY BYPASS GRAFT SURGERY IN PATIENTS WITH TYPE 2 DIABETES \\ Objectives: Evaluation of left ventricular function} by echocardiography before and after coronary artery bypass graft surgery in patients with type 2 diabetes. Subjects and methods: a cross-sectionnal observation study in 46 patients with type 2 diabetes were included coronary artery bypass graft surgery from $8 / 2020$ to $8 / 2021$ at Hanoi Heart Hospital. Results: Mean age $66 \pm 8.73$; male/female ratio is $2.83 / 1 ; 43.5 \%$ of patients smoke; the rate of chest pain was $69.6 \%$ and NYHA III - IV accounted for $28.6 \%$. Echocardiographyresult: The number of disturbance areas before and after surgery were $3.52 \pm 5.39$ and $2.54 \pm 4.87$. Echocardiography resultin the group with preoperative $\mathrm{EF}<50 \%$ : Dd before and after surgery were $53.3 \pm 7,12 \mathrm{~mm}$ and $50,3 \pm$ $6,93 \mathrm{~mm}$. Ds before and after surgery were 40,4 $8,44 \mathrm{~mm}$ and $36,8 \pm 8,05 \mathrm{~mm}$, Vd before and after surgery were $142,2 \pm 48,77 \mathrm{ml}$ and $124,2 \pm 38,9 \mathrm{ml}$. Vs before and after surgery were $77 \pm 42,13 \mathrm{ml}$ and 61,1 $\pm 29,47 \mathrm{ml}$, LVMI before and after surgery were $135,5 \pm$ 44,61 grams and 117,4 $\pm 30,17$ grams, EF before and after surgery were $39,22 \pm 8,4 \%$ and $45,83 \pm 13,39 \%$ There was a statistically significant improvement in ultrasound parameters in the group with preoperative $\mathrm{EF}<50 \%$ : EF increased significantly while cardiac chamber volume, chamber size and left ventricular muscle mass decreased. Particularly in the EF group, the parameters decreased but there was no statistical significance. Conclusion: Coronary bypass surgery significantly improved left ventricular function immediately after surgery in the group with low EF before surgery.

Keywords: Coronary artery bypass grafting, diabetes, left ventricular function 


\section{I. ĐĂT VẤN ĐỀ}

Bệnh mạch vành và đái tháo đường là những nguyên nhấn hàng đâu gây tàn phế và tử vong ở những người trên 35 tuổi trên thế giới và Việt Nam. ${ }^{1}$ Giữa bệnh mạch vành và đái tháo đường có mối liên quan đặc biệt: đái tháo đường làm tăng nguy cơ măc bệnh mạch vành và ngược lại, bệnh mạch vành cũng làm tăng tỉ lệ tử vong ở bệnh nhân mạch vành. ${ }^{2}$ Việc đánh giá chức năng tim ở các bệnh nhân đái tháo đường type II sau phẫu thuật bắc câu chủ vành thông qua chức năng thất trái có ý nghĩa tiên lượng lớn. Vì vậy, chúng tôi tiến hành nghiên cứu này nhằm khảo sát đặc điểm chức năng thất trái sau phẫu thuật bắc câu chủ vành ở bệnh nhân có đái tháo đường type 2.

\section{II. ĐỐI TƯƠNG VÀ PHƯƠNG PHÁP NGHIÊN CỨU}

Nghiên cứu mô tả cắt ngang trên 46 bệnh nhân đái tháo đường type 2 được chẩn đoán theo tiêu chuẩn của ADA (2019), có hẹp/tắc mạch vành được chỉ định phẫu thuật bắc câu chủ vành theo ESC 2014; được phẫu thuật bắc câu chủ vành đơn thuân (không kèm theo phẫu thuật tim khác) từ 8/2020 đến 8/2021 tại bệnh viện Tim Hà Nội. Bệnh nhân được thăm khám và siểu âm tim trước và sau mổ. Số liệu được xử lý bằng phần mềm SPSS 20. Sử dụng kiểm định $T$ Student cho các biến liên tục và chi square cho các biến rời rạc với giá trị $p<0,05$ có ý nghĩa thống kê.

\section{KẾT QUẢ NGHIÊN CỨU}

Trong thời gian từ 8/2020 đến $8 / 2021$ chúng tôi có 46 bệnh nhân phù hợp với nghiên cứu.

1. Đặc điểm chung của bệnh nhân nghiên cứu

Bảng 1. Một số đặc điểm trước phẫu thuật

\begin{tabular}{|c|c|c|}
\hline \multicolumn{2}{|r|}{ Đặc điểm } & $\begin{array}{c}\text { Kết quả n }(\%) \text { hoăc } \\
\text { trung bình } \pm 2 S D\end{array}$ \\
\hline \multicolumn{2}{|r|}{ Tuối (năm) } & $66 \pm 8,73$ \\
\hline \multicolumn{2}{|r|}{ Nam giới } & $34(73,9 \%)$ \\
\hline \multicolumn{2}{|r|}{ BMI } & $23,56 \pm 2,45$ \\
\hline \multirow{4}{*}{$\begin{array}{c}\text { Yếu tố } \\
\text { nguy } \\
\text { cơ }\end{array}$} & Tăng huyết áp & $45(97,8 \%)$ \\
\hline & Hút thuốc lá & $20(43,5 \%)$ \\
\hline & Rối loạn mõ̃ máu & $30(65,2 \%)$ \\
\hline & Thừa cân, béo phì & $23(50 \%)$ \\
\hline \multirow{4}{*}{ NYHA } & I & $1(2,2 \%)$ \\
\hline & II & $32(69,6 \%)$ \\
\hline & III & $12(26,1 \%)$ \\
\hline & IV & $1(2,2 \%)$ \\
\hline
\end{tabular}

Nhân xét: Tuối trung bình trong nghiên cứu là $66 \pm 8,73$ tuổi, nam chiếm 73,9\%. Về các yếu tố nguy cơ, tăng huyết áp vẫn là nguyên nhân hay gặp.

\section{Biến đổi lâm sàng và cân lâm sàng sớm sau phẫu thuật}

Bảng 2. Biến đổi một số kêt quả lâm sàng và cận lâm sàng sớm sau mổ

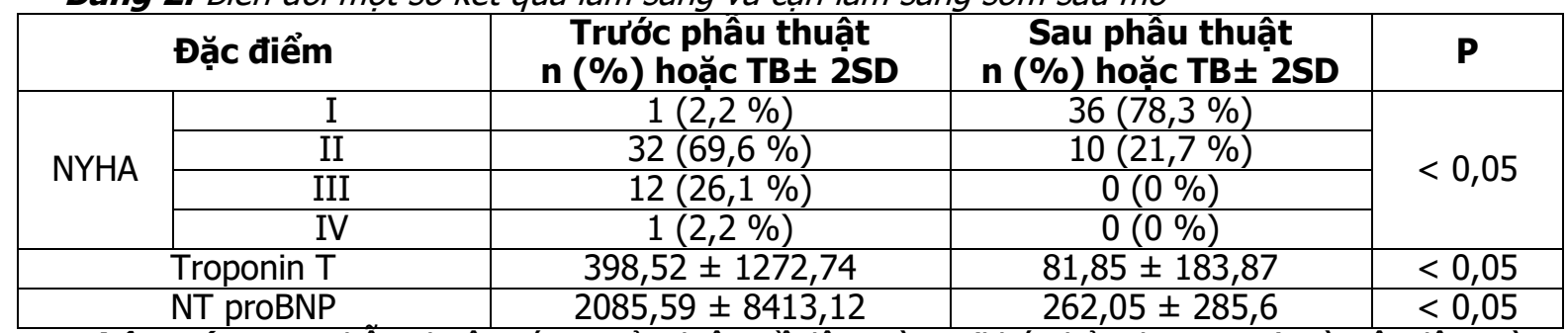

Nhận xét: Sau phẫu thuật có sự cải thiện về lâm sàng (khó thở, đau ngực) và cận lâm sàng (troponin T, NT proBNP) so với trước mổ.

3. Đặc điểm chức năng thất trái trên siêu âm tim trước và sau phẫu thuật

Bảng 3. Các thông số siêu âm tim trước và sau phấu thuật.

\begin{tabular}{|c|c|c|c|}
\hline Đặc điểm & $\begin{array}{c}\text { Trước phâu thuật } \\
\text { TB } \pm \text { 2SD }\end{array}$ & $\begin{array}{c}\text { Sau phâu thuật } \\
\text { TB } \pm \mathbf{2 S D}\end{array}$ & $\mathbf{p}$ \\
\hline Đường kính TT tâm trương & $46,2 \pm 6,97$ & $44,16 \pm 6,97$ & $\mathbf{0 , 0 2 2}$ \\
\hline Đường kính TT tâm thu & $30,09 \pm 7,7$ & $29,57 \pm 6,47$ & 0,485 \\
\hline Bề dày VLT tâm trương & $10,86 \pm 2,1$ & $10,67 \pm 1,7$ & 0,577 \\
\hline Bề dày TSTT tâm trương & $9,72 \pm 1,64$ & $9,41 \pm 1,57$ & 0,32 \\
\hline Chỉ số khối cơ thất trái & $108,13 \pm 33,62$ & $99,95 \pm 27,5$ & $\mathbf{0 , 0 2 7}$ \\
\hline EF Simpson & $55,33 \pm 11,49$ & $55,13 \pm 10,05$ & 0,874 \\
\hline RLVĐ vùng & $26(56,5 \%)$ & $20(43,5 \%)$ & $\mathbf{0 , 0 1 7}$ \\
\hline Số vùng rối loạn & $3,52 \pm 5,39$ & $2,54 \pm 4,87$ & $\mathbf{0 , 0 1 3}$ \\
\hline
\end{tabular}

Nhận xét: So với trước phẫu thuật, chỉ số khối cơ thất trái và đường kính tâm trương thất trái giảm có ý nghĩa. Rối loạn vận động vưng có sự cải thiện so với trước phẫu thuật. 
Bảng 4. Các thông số siêu âm tim trước và sau phẫu thuật ở nhóm có EF binh thường (>50\%) và nhóm EF giảm trước phẫu thuật.

\begin{tabular}{|c|c|c|c|c|c|c|}
\hline \multirow{2}{*}{$\begin{array}{l}\text { Đăćc } \\
\text { điểm }\end{array}$} & \multicolumn{2}{|c|}{ Nhóm EF bình thường } & \multirow[b]{2}{*}{$\mathbf{p}$} & \multicolumn{2}{|c|}{ Nhóm EF giảm } & \multirow[b]{2}{*}{$\mathbf{P}$} \\
\hline & Trước PT & Sau PT & & Trước PT & Sau PT & \\
\hline Dd & $44,22 \pm 5,58$ & $42,26 \pm 6,03$ & 0,091 & $53,3 \pm 7,12$ & $50,3 \pm 6,93$ & 0,009 \\
\hline Ds & $27,22 \pm 4,36$ & $27,56 \pm 4,25$ & 0,663 & $40,4 \pm 8,44$ & $36,8 \pm 8,05$ & 0,010 \\
\hline $\mathrm{Vd}$ & $91,5 \pm 27,25$ & $84,06 \pm 26,85$ & 0,14 & $142,2 \pm 48,77$ & $124,2 \pm 38,9$ & 0,012 \\
\hline Vs & $28,86 \pm 11,61$ & $31,06 \pm 12,26$ & 0,347 & $77 \pm 42,13$ & $61,1 \pm 29,47$ & 0,005 \\
\hline LVMI & $100,53 \pm 25,85$ & $95,1 \pm 25,04$ & 0,134 & $135,5 \pm 44,61$ & $117,4 \pm 30,17$ & 0,027 \\
\hline EF & $60,41 \pm 5,81$ & $58,53 \pm 6,42$ & 0,144 & $39,22 \pm 8,4$ & $45,83 \pm 13,39$ & 0,048 \\
\hline
\end{tabular}

Nhân xét. Trong nhóm có suy tim EF giảm, các chỉ số thể tích và chức năng tâm thu thất trái toàn bộ có sự cải thiện đáng kể, $p<0,05$.

Bảng 5. Chức năng tâm trương thất trái trước và sau phẫu thuật trên siêu âm tim

\begin{tabular}{|c|c|c|c|}
\hline Đặc điểm & $\begin{array}{c}\text { Trước phâu thuật } \\
\text { TB } \pm \text { SD }\end{array}$ & $\begin{array}{c}\text { Sau phâu thuật } \\
\text { TB } \pm \text { SD }\end{array}$ & $\mathbf{p}$ \\
\hline LAVI & $33,53 \pm 7,71$ & $31 \pm 7,35$ & $\mathbf{0 , 0 1 0}$ \\
\hline E van hai lá $(\mathrm{cm} / \mathrm{s})$ & $64,06 \pm 18,11$ & $68,37 \pm 19,81$ & 0,072 \\
\hline A van hai lá $(\mathrm{cm} / \mathrm{s})$ & $85,7 \pm 20,15$ & $77,41 \pm 17,84$ & $\mathbf{0 , 0 0 1}$ \\
\hline $\mathrm{E}^{\prime}$ vách $(\mathrm{cm} / \mathrm{s})$ & $5,33 \pm 1,52$ & $5,97 \pm 1,63$ & $\mathbf{0 , 0 0 5}$ \\
\hline $\mathrm{E}^{\prime}$ thành bên $(\mathrm{cm} / \mathrm{s})$ & $7,74 \pm 2,35$ & $8,07 \pm 1,93$ & 0,331 \\
\hline E/E' trung bình & $10,39 \pm 3,27$ & $10,31 \pm 3,18$ & 0,867 \\
\hline V max hở ba lá $(\mathrm{m} / \mathrm{s})$ & $2,33 \pm 0,25$ & $2,3 \pm 0,13$ & 0,507 \\
\hline RLCNTTr & $15(32,6 \%)$ & $9(19,5 \%)$ & $\mathbf{0 . 0 0 4}$ \\
\hline
\end{tabular}

Nhận xét: Chức năng tâm trương thất trái có sự cải thiện sau phẫu thuật.

\section{BÀN LUÂN}

1. Đặc điểm trước phẫu thuật. Tuổi trung bình trong nghiên cứu là $66 \pm 8,73$ tuổi, cao nhất là 43 tuổi và thấp nhất là 81 tuổi. Nam chiếm đa số với tỷ lệ nam/nữ là 2,83/1 (bảng 1), điều này có thể liên quan đến tỷ lệ hút thuốc lá ở nam giới cao hơn. Chỉ số khối trung bình trong nghiên cứu là $23,56 \pm 2,45$, cụ thể chúng tôi ghi nhận $50 \%$ bệnh nhân có thừa cân-béo phì. Các kết quả tương tự về tuổi và tỷ lệ ưu thể là nam giới cũng được ghi nhận trong các nghiên cứu của Zoltán Szabó và cộng sử trên 540 bệnh nhân đái tháo đường được phấu thuật $\mathrm{CABG}$, với độ tuổi trung bình là $64,2 \pm 9,4$ và tỳ lệ nam giới chiếm $71,7 \%$, và $B M I$ trung bình là $28,0 \pm 4,1$; Akhil Kapur và cộng sự với 254 bệnh nhân có kết quả tuổi trung bình $63,6 \pm 9,1$, nam giới chiếm tới $77,9 \%$ và BMI trung bình là $29,4 \pm$ 5,3 ; Arie Pieter Kappetein và cộng sự ${ }^{5}$ khi nghiên cứu trên 451 bệnh nhân đái tháo đường được phẫu thuật CABG do bệnh lý thân chung và/hoặc bệnh 3 thân động mạch vành với tuổi trung bình là $65,4 \pm 9,2$ và $71,0 \%$ bệnh nhân là nam giới, BMI trung bình là $29,5 \pm 5,2$, hay Otso Järvinen và cộng sự nghiên cứu trên 508 bệnh nhân được phẫu thuật bắc cầu chủ vành với 74 bệnh nhẩn có bệnh lý đái tháo đường, trong nhóm có tuổi trung bình là $63,0 \pm 8,3$ và tỷ lệ nam giới là $78,4 \%$ (bảng 8 ). So với những nghiên cứu này,
BMI trung bình trong nghiên cứu của chúng tôi thấp hơn, điều này có thể là do sự khác biệt về chế độ ăn cũng như lối sống của các nước phương tây.

Tăng huyết áp là một yếu tố nguy cơ của bệnh lý mạch vành và chức năng thất trái. Chỉ huyết áp tẩm thu và tâm trương trung bình trong nghiên cứu lần lượt là $133,28 \pm 16,22$ và $75,39 \pm$ $11,28 \mathrm{mmHg}$, các kết quả này tương tự nghiên cứu của Akhil Kapur và cộng sự với giá trị tương ứng là là $137,3 \pm 18,7$ và $73,3 \pm 12,0 \%$. Mặc dù các giá trị huyết áp trong nghiên cứu của chúng tôi có giá trị ở ngưỡng bình thường, tỷ lệ bệnh nhân có bệnh lý tăng huyết áp được ghi nhận trước đó là $97,8 \%$ và đa số đang được điều trị huyết áp trước đó. Tác giả Zoltán Szabó chỉ ghi nhận tỷ lệ tăng huyết áp là 49,3\%, trong khi đó các nghiên cứu của tác giả Akhil Kapur và Arie Pieter Kappetein đều báo cáo các tỷ lệ tăng huyết áp ở mức với các giá trị tương ứng là $80,6 \%$ và $70 \% .^{3-5}$

Các yếu tố nguy cơ trước mổ khác được ghi nhận trong nghiên cứu như hút thuốc lá chiếm $(43,5 \%)$, rối loạn mõ máu $(65,2 \%)$. Tỷ lệ rối có rối loạn mõ máu trong nghiên cứu của chúng tôi thấp hơn so với tác giả Akhil Kapur $(87,3 \%)$ và tác giả Arie Pieter Kappetein (82\%). ${ }^{4,5}$ Tỷ lệ có tiền sử hoặc đang hút thuốc lá trong nghiên cứu của chúng tôi cao hơn so với tác giả Akhil Kapur là $36,6 \%$. 
Đau ngực và khó thở là các triệu chứng chính khi vào viện, tỷ lệ $B N$ có đau ngực trong nghiên cứu là $69,6 \%$. Mức đô khó thở theo NYHA là mức NYHA II với tỷ lệ $69.6 \%$. Zoltán Szabó và cộng sự ghi nhận tỷ lệ NYHA III chiếm cao nhất với $44 \%$ và tỷ lệ NYHA IV tới 33,5\%, tác giả Scott E. Woods và cộng sự đánh giá trên 2178 trường hợp phẫu thuật bắc cầu chủ vành ở bệnh nhân ĐTĐ type II cho thấy tỷ lệ NYHA III và IV lần lượt là $34,6 \%$ và $26,3 \%$, tỷ lệ NYHA I và II tương ứng là $14,3 \%$ và $24,8 \%$. So với những nghiên cứu này, kết quả của chúng tôi cho thây mức độ khó thở nhẹ hơn.

Trên kết quả chụp động mạch vành, chúng tôi ghi nhận tỷ $100 \%$ bệnh nhân có tổn thương động mạch liên thất trước, có 37 bệnh nhân có tổn thương ĐM mũ chiếm 80,4\%, 39 bệnh nhân tổn thương ĐMV phải chiếm tỷ lệ $84,8 \%$, Tổn thương thân chung có 14 bệnh nhẩn chiếm tỷ lệ 30,4\%. Với những tổn thương phức tạp 3 thân hoặc bệnh lý thân chung, đặc biệt là ở đối tượng đái tháo đường, thì chỉ định phấu thuật bắc cầu chủ vành thường là lựa chọn được ưu tiên với những kết quả tích cực hơn so với điều trị nội khoa và can thiệp mạch vành qua da. Đặc điểm về vị trí tổn thương được ghi nhận cũng thay đổi giữa các nghiên cứu: tác giả Akhil Kapur và cộng sự cho kết quả tỷ lệ bệnh lý 3 thân là $59,7 \%$, bệnh 2 thân là 34,7\%, thân chung là $2 \%$ và đoạn gần LAD là $4,7 \%$, trong khi đó Otso Järvinen và cộng sự lại nhận xét rằng tỷ lệ có hẹp $>50 \%$ LM chiếm tới $80,8 \%$.

2. Đặc điểm chức năng thất trái trên siêu âm tim trước và sau phẫu thuật. Về kích thước và thể tích thất trái trên siêu âm, các kết quả ghi nhận trên siêu âm tại thời điểm trước và sau phẫu thuật cho thây sự giảm xuống có ý nghĩa thống kê của các thông số $\mathrm{Dd}, \mathrm{Vd}$, LVM, LVMI $(p<0,05)$. Tuy nhiên, không thấy sự thay đổi ý nghĩa về giá trị của Ds, Vs, bề dày VLT tâm trương, bề dày TSTT tâm trương trước và sau (bảng 3). Tác giả Camilla L. Søraas và cộng sự nghiên cứu trên 42 trường hợp phẫu thuật bắc cầu chủ vành cho thấy tại thời điểm sớm sau mổ có giảm ý nghĩa các chỉ số $D s, V d$ và không thay đổi có ý nghĩa ở các chỉ số Dd, Vs, tuy nhiên với kết quả theo dõi dài hạn chỉ thây sự thay đổi ý nghĩa về Dd so với trước phẫu thuật $(p<0,05)$.

Giá trị EF trung bình trước mổ là 55,33 \pm $11,49 \%$, đa số các bệnh nhân trong nghiên cứu đều có giá trị $\mathrm{EF}$ bình thường trước phẫu thuật với tỷ lệ $E F$ giảm chiếm $21,7 \%$. Kết quả của chúng tối tương tự với tác giả Akhil Kapur và cộng sự với EF trung bình là $60,0 \pm 12,7 \%$,
Otso Järvinen và cộng sự cho thây tỷ lệ EF giảm $(<50 \%)$ là $37 \%$. Tỷ lệ EF giảm nặng $<35 \%$ trong nghiên cứu của Zoltán Szabó và cộng sự ${ }^{3}$ là $6,8 \%$. Ở nhóm bệnh nhân có EF giảm trước phẫu thuật chúng tôi thấy rằng có sự cải thiện có ý nghĩa về các thông số $\mathrm{Dd}, \mathrm{Ds}, \mathrm{Vd}, \mathrm{Vs}$, $\mathrm{LVM}$ và LVMI và $E F$ so với trước mổ $(p<0,05)$ mặc dù không thấy sự khác biệt về các giá trị VLT và TSTT $(p<0,05)$ (bảng 3.4). Trong khi đó ở nhóm có $\mathrm{EF}$ bình thường trước phẫu thuật không thấy sự thay đổi ở các kết quả siêu âm sau mổ về những thông số tương tự $(p>0,05)$.

Tỷ lệ bệnh nhân có rối loạn vùng giảm đi đáng kể so với thời điểm trước mổ từ 56,5\% xuống 43,5 \% ( $p<0,05)$. Đồng thời, số vùng có rối loạn giảm so với thời điểm trước phẫu thuật từ $3,52 \pm 5,39$ xuống $2,54 \pm 4,87(p<0,05)$. Điều này cho thấy giá trị giúp cải thiễ̂n chức năng tâm thu thất trái từng vùng của phẫu thuật ở bệnh nhân có bệnh lý mạch vành và đái tháo đường. Có 27 trong tổng số 46 bệnh nhân nghiên cứu có rối loạn vận động vùng của thành thất trái trước phẫu thuật, ở các mức độ khác nhau từ giảm vận động đến phình thành tim. Tiến hành tính điểm vận động cho từng đoạn vùng trên những bệnh nhân này: Thành trước (3 đoạn), thành trước vách (3 đoạn), thành dưới vách (2 đoạn), thành dưới (3 đoạn), thành dưới bên ( 2 đoạn), thành trước bên( 3 đoạn) và mỏm.Vân động thành dưới vách, thành dưới và thành dưới bên được cải thiện có ý nghĩa thống kê sau phẫu thuật 7 ngày $(p<0,05)$. Vận động thành trước, thành trước vách, thành trước bên và mỏm không có khác biệt có ý nghĩa thống kê $(p<0,05)$ (bảng 7). Theo tác giả Camilla L. Søraas và cộng sự trong nghiên cứu về đặc điểm cải thiện chức năng tim sớm trên siêu âm sau phẫu thuâtt bắc cầu chủ vành được thực hiện ở 42 bệnh nhân cho thây chỉ số vận động thành giảm xuống tại thời điểm sớm sau mổ 2 ngày, từ $1,19 \pm 0,25$ xuống $1,17 \pm 0,24(p=0,05)$ và sau 7 tuần chỉ còn $1,14 \pm 0,23(p=0,01)$. Có lẽ có sự khác biệt này là do thời gian theo dõi khác nhau giữa các nghiên cứu. Ngoài ra, chúng tôi ghi nhận sự thay đổi có ý nghĩa thống kê của các thông số LAVI, $A V H L$ và $E^{\prime}$ vách sau phẫu thuât so với thời điểm trước phẫu thuật. Sau phấu thuật tỷ lê bệnh nhân có rối loạn chức năng tâm trương thất trái giảm so voiws trước phẫu thuật là có ý nghĩa thống kê với $(p<0.05)$ Nhưng không có khác biệt về các thông số $E V H L, E^{\prime}$ thành bên, $E / E^{\prime}$ trung bình, $V$ max hở ba lá $(p>$ $0,05)$. 


\section{KẾT LUÂN}

Phẫu thuật bắc cầu chủ vành là lựa chon được ưu tiên đối với những trường hợp có tổn thương hẹp, tắc động mạch vành phức tạp ở bệnh nhân có đái tháo đường. Những kêt quả đánh giá bước đầu cho thấy có sự cải thiện sớm sau mổ về chức năng thất trái trên lâm sàng, xét nghiệm và siêu âm tim, đặc biệt là ở nhóm có EF giảm trước phẫu thuật.

\section{TÀI LIẸU THAM KHẢO}

1. Phạm Mạnh Hùng. Lâm Sàng Tim Mạch Học.; 2019.

2. Nguyễn Công Hựu. Nghiên cứu kết quả phẫu thuật bắc cầu chủ vành ớ bệnh nhân hẹp ba thân động mạch vành tại trung tâm tim mạch bệnh viện E. Published online 2018.

3. Szabó $Z$, Håkanson E, Svedjeholm R. Early postoperative outcome and medium-term survival in 540 diabetic and 2239 nondiabetic patients undergoing coronary artery bypass grafting. Ann Thorac Surg. 2002;74(3):712-719. doi:10.1016/S0003-4975(02)03778-5

4. Kapur A, Hall RJ, Malik IS, et al. Randomized Comparison of Percutaneous Coronary Intervention
With Coronary Artery Bypass Grafting in Diabetic Patients. J Am Coll Cardiol. 2010;55(5):432-440. doi:10.1016/j.jacc.2009.10.014

5. Kappetein AP, Head SJ, Morice M-C, et al. Treatment of complex coronary artery disease in patients with diabetes: 5-year results comparing outcomes of bypass surgery and percutaneous coronary intervention in the SYNTAX trialt. Eur J Cardiothorac Surg. 2013;43(5):1006-1013. doi:10.1093/ejcts/ezt017

6. Järvinen $\mathrm{O}$, Hokkanen $M$, Huhtala $H$. Diabetics have Inferior Long-Term Survival and Quality of Life after CABG. Int J Angiol. 2019;28(1):50-56. doi: $10.1055 / \mathrm{s}-0038-1676791$

7. Woods SE, Smith JM, Sohail S, Sarah A, Engle A. The Influence of Type 2 Diabetes Mellitus in Patients Undergoing Coronary Artery Bypass Graft Surgery: An 8-Year Prospective Cohort Study. Chest. doi:10.1378/chest.126.6.1789

8. Søraas CL, Larstorp ACK, Mangschau A, Tønnessen $T$, Kjeldsen SE, Bjørnerheim $R^{\prime}$. Echocardiographic demonstration of improved myocardial function early after coronary artery bypass graft surgery z. $^{2}$. Interact Cardiovasc Thorac Surg. doi:10.1510/icvts.2010.260414
2011;12(6):946-951.

\section{PHÂN TÍCH THƯC TRANG KÊ ĐƠN DỰA TRÊN BẰNG CHỨNG Ở CÁC BÊ̂NH NHẨN SUY TIM TÂM THU TRONG CHƯO'NG TRÌNH QUẢN LÝ NGOẠI TRÚ TẠI BỆNH VIỆN TIM HÀ NộI}

\section{TÓM TẮT}

Mục tiêu: hướng dẫn điều trị của Bộ $Y$ tễ và Hội tim mạch nhấn mạnh vai trò của việc kê đơn thuổc dựa trền bằng chứng trên bệnh nhân suy tim tâm thu. Mặc dù vây, nghiên cứu trong thực tế cho thấy mức độ tuân thủ còn thấp. Do đó, nghiên cứu này được thực hiện nhằm phân tích thực trạng kê đơn dựa trển bằng chứng ở các bệnh nhân suy tim tâm thu trong chương trình quản lý ngoại trú tại bệnh viện Tim Hà Nội. Đối tượng và phương pháp nghiên cứu: Nghiên cứu mô tả, cắt ngang trên 134 bệnh nhân suy tim tâm thu tái khám định kỳ đủ 12 tháng trong năm 2018. Thông tin về lâm sàng, cận lâm sàng, phác đồ điều trị được ghi nhận dựa trên bệnh án ngoại trú. Chống chỉ định, liều đích của $A C E I / A R B$ và $B B$ được đánh giá dựa trên hướng dấn điều trị suy tim của Bộ Y tế 2020 và Hội tim mạch châu Âu 2016. Kết quả nghiên cứu: Tỳ lệ đơn kê phối hợp thuốc ACEI/ARB

\footnotetext{
${ }^{1}$ Bệnh viện Tim Hà Nội,

2Trường đai hoc Dước Hà Nôi

Chịu trách nhiệm chính: Vũ Quỳnh Nga

Email: ngavuq@gmail.com

Ngày nhận bài: 10.9.2021

Ngày phản biện khoa học: 29.10.2021

Ngày duyệt bài: 11.11.2021
}

\section{Nguyễn Hũu Duy ${ }^{2}$, Nguyễn Thị Liên Hương ${ }^{2}$, Vũ Quỳnh Nga $^{1}$}

và $\mathrm{BB}$ theo khuyến cáo là $92,5 \%$. Tuy nhiên, chỉ có $17,2 \%$ và $23,1 \%$ bệnh nhân được tiếp nối cùng 1 thuốc $A C E I / A R B$ và BB trong suốt 12 tháng. Nghiên cứu cho thấy thay đổi bác sĩ ở các lần tái khám làm giảm tính tiếp nối trong kê đơn $(\mathrm{p}<0,001)$. Không có bệnh nhân nào được kê liều đích thuốc ACEI/ARB hoặc $\mathrm{BB}$. Mặc dù vậy, $84,0-88,3 \%$ bệnh nhân đủ điều kiện đế tăng liêuu $A C E I / A R B$ và BB. Kết luận: liều các thuốc $A C E I / A R B$ và $B B$ nên đước tăng dần đêên liều đích hoặc liêuu tối đa dung nạp để giảm nguy cơ tử vong và nhập viện do suy tim. chứng.

Tư khóa: Suy tim tâm thu, kê đơn dựa trên bằng

\section{SUMMARY \\ PRESCRIPTION OF GUIDELINE-DIRECTED MEDICATION IN OUTPATIENTS WITH SYSTOLIC HEART FAILURE IN HANOI HEART HOSPITAL}

Background and objectives: Ministry of Health's clinical pathways and guideline of ESC emphasize the role of evidence-based prescribing in patients with heart failure. However, recent studies showed the gaps between guideline recommendations and clinical practice in management of heart failure with reduced ejection fraction. This study aimed to analyse the 